\title{
The three syndromes and six Chinese patent medicine study during the recovery phase of COVID-19
}

\author{
Xuedong An ${ }^{1,2 \dagger}$, Liyun Duan ${ }^{1,2 \dagger}$, Yue Hong Zhang ${ }^{1,2 \dagger}$, De Jin ${ }^{1,2}$, Shenghui Zhao ${ }^{1,3}$, Rong Rong Zhou ${ }^{1,3}$, \\ Yingying Duan ${ }^{1,3}$, Fengmei Lian ${ }^{1 *}$ and Xiaolin Tong ${ }^{1 *}$
}

\begin{abstract}
The coronavirus disease 2019 (COVID-19), caused by severe acute respiratory syndrome coronavirus-2 (SARS-CoV-2), first broke out in Wuhan, China, in 2019. SARS-CoV-2 develops many types of mutations (such as B.1.1.7), making diagnosis and treatment challenging. Although we now have a preliminary understanding of COVID-19, including pathological changes, clinical manifestations, and treatment measures, we also face new difficulties. The biggest problem is that most COVID-19 patients might face sequelae (e.g., fatigue, sleep disturbance, pulmonary fibrosis) during the recovery phase. We aimed to test six Chinese patent medicines to treat three major abnormal symptoms in COVID-19 patients during the recovery phase, including cardiopulmonary function, sleep disturbance, and digestive function. We launched the "three syndromes and six Chinese patent medicines" randomized, double-blind, placebocontrolled, multicenter clinical trial on April 10,2020. The results showed that Jinshuibao tablets and Shengmaiyin oral liquid significantly improved the cardiopulmonary function of recovering COVID-19 patients. Shumian capsules, but not Xiaoyao capsules, significantly improved patients' sleep disorders. This might be because the indication of Xiaoyao capsules is liver qi stagnation rather than psychological or emotional problems. Xiangsha Liujun pills and Ludangshen oral liquid significantly improved digestive function. Our research provides a guideline for treating COVID-19 sequelae in patients during the recovery period based on high-quality evidence.
\end{abstract}

Keywords: COVID-19, Recovery period, COVID-19 sequelae, Three syndromes and six Chinese patent medicines

\section{Introduction}

The coronavirus disease 2019 (COVID-19) caused by severe acute respiratory syndrome coronavirus-2 (SARSCoV-2) first broke out in Wuhan, China, in 2019. The World Health Organization (WHO) declared the outbreak a public health emergency on January 30, 2020. As of January 15, 2021, there were more than 93 million confirmed infections, and the global death toll had reached

\footnotetext{
*Correspondence: Lfm565@sohu.com; Tongxiaolin@vip.163.com ${ }^{\dagger}$ Xuedong An, Liyun Duan and YueHong Zhang contributed equally to this study and are co-first authors

${ }^{1}$ Department of Endocrinology, Guang'anmen Hospital, China Academy of Chinese Medical Sciences, Beijing 100053, China

Full list of author information is available at the end of the article
}

2,000,000, according to Johns Hopkins University [1]. Of these, severe/critically ill patients account for a large proportion of the deaths [2,3]. Approximately $20 \%$ of COVID-19 patients developed pulmonary infiltration, some of which developed a severe form of the disease [4], especially the elderly and patients with underlying chronic diseases such as heart diseases and diabetes [5, 6]. Sepsis is the most common complication, followed by respiratory failure, acute respiratory distress syndrome (ARDS), heart failure, and septic shock [7]. As of February 11, 2020, the overall fatality rate of COVID-19 patients in China was $2.3 \%$. However, the overall case fatality rate in patients aged $70-79$ years was $8.0 \%$, and it was $14.8 \%$ in patients aged $\geq 80$ years [8]. We now have

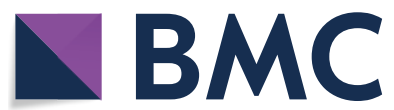

(c) The Author(s) 2021. This article is licensed under a Creative Commons Attribution 4.0 International License, which permits use, sharing, adaptation, distribution and reproduction in any medium or format, as long as you give appropriate credit to the original author(s) and the source, provide a link to the Creative Commons licence, and indicate if changes were made. The images or other third party material in this article are included in the article's Creative Commons licence, unless indicated otherwise in a credit line to the material. If material is not included in the article's Creative Commons licence and your intended use is not permitted by statutory regulation or exceeds the permitted use, you will need to obtain permission directly from the copyright holder. To view a copy of this licence, visit http://creativeco mmons.org/licenses/by/4.0/. The Creative Commons Public Domain Dedication waiver (http://creativecommons.org/publicdomain/ zero/1.0/) applies to the data made available in this article, unless otherwise stated in a credit line to the data. 
a preliminary understanding of COVID-19, including its pathology, clinical manifestations, and treatment.

\section{COVID-19}

\section{SARS-CoV-2}

SARS-CoV-2 is a positive-sense single-strand RNA virus of the Betacoronavirus lineage $\mathrm{B}$ and closely related to SARS-CoV [9]. There are no definitive conclusions as to the source of SARS-CoV-2. The genome sequence of coronaviruses carried by bats and pangolins was $90-96 \%$, similar to SARS-CoV-2, but it is still uncertain whether any of these was the animal source of the first human infection [10].

\section{The pathology of COVID-19}

COVID-19 transmission is primarily through the mouth by air, aerosol, contact, and feces [11]. Some studies have confirmed that SARS-CoV-2 could contaminate surfaces and medical equipment, especially in hospitals dedicated to COVID-19 patients [12]. After the human host is infected, SARS-CoV-2 infects alveolar epithelial cells by binding the angiotensin-converting enzyme II (ACE2) receptor. Binding to the receptor mediates the subsequent fusion between the virus envelope and the host cell membrane, allowing the virus to enter $[13,14]$. By examining tissue samples from seven organs, including the lungs, spleen, liver, heart, kidneys, thyroid, and the testicles of patients who died from COVID-19 in 2019, it was found that the lungs of these patients had diffuse alveolar damage, pulmonary fibrosis, and neutrophil infiltration; fatty metaplasia, and sometimes infarction in the liver; myocardial edema and interstitial lymphocyte infiltration of the heart; and acute tubular injury in the kidneys [15]. These are related to a series of excessive reactions due to SARS-CoV-2 infection, including cytokine storm, immune system disorders, and abnormal blood coagulation. The expression levels of interleukin 1-B (IL-1B), interferon- $\gamma$ (IFN- $\gamma$ ), chemokine-10 (IP-10), and monocyte chemoattractant protein 1 (MCP-1) are very high in COVID-19 patients [16]. Monocytes are circulating innate immune cells and might be the main participants in related pathologies in cytokine storm and COVID-19 [17]. Cytokine storm can cause ARDS or multiple organ failure outside the lungs and is an important factor leading to worsening of the disease or even death $[18,19]$. Severe complications of COVID-19 include ARDS, embolism or pulmonary thrombosis, and a hypercoagulable state [20]. The incidence of alveolar capillary thrombosis in COVID-19 patients is nine times higher than in ordinary influenza patients [21]. Thrombocytopenia seems to be a key indicator of patient deterioration [22], and focal damage of pulmonary microvascular circulation is the primary mechanism of a fatal lung disease caused by SARS-CoV-2 [23]. Anticoagulation therapy was associated with improved prognosis in critically ill COVID-19 patients [24] who usually show enhanced coagulation and thrombosis $[25,26]$. The mechanism might be the combined effect of the renin-angiotensin system and cytokine storm, which could mediate an increase in fibrinogen [27], extensive formation of microvascular thrombosis [28], disseminated intravascular coagulation (DIC), and secondary fibrinolysis [29].

\section{Clinical features of COVID-19}

Common clinical manifestations of COVID-19 include fever $(88.7 \%)$, cough $(67.8 \%)$, fatigue $(38.1 \%)$, sputum production $(33.7 \%)$, shortness of breath $(18.7 \%)$, sore throat (13.9\%), and headache (13.6\%) [30]. Moreover, when lung cells are infected with SARS-CoV-2, the effector $\mathrm{CD} 4+\mathrm{T}$ cells reach the small intestine through the intestine-pulmonary axis, causing some gastrointestinal symptoms [11], including diarrhea (3.8\%) and vomiting (5.0\%) [30, 31]. Many cytokines enter through the bloodbrain barrier and affect the central nervous system function, resulting in symptoms of the central nervous system [32]. However, all these symptoms do not seem specific, as some patients may develop a fever, while others may not $[2,33]$. Critically ill patients might suddenly deteriorate in the later stages of the disease or during the recovery process. ARDS and multiple organ failure occur swiftly, leading to rapid death [34].

\section{Diagnosis, prevention, and treatment of COVID-19}

Many technologies can be used to diagnose SARS-CoV-2 infection, including reverse transcription-polymerase chain reaction (RT-PCR), serological tests, point-of-care testing, smartphone monitoring of infectious diseases, nanotechnology-based methods, biological sensors, and metagenomic sequencing based on amplicons [35]. Saliva specimens could be considered a reliable and less resource-intensive alternative for screening asymptomatic SARS-CoV-2 infected patients [36].

COVID-19 prevention includes various forms of isolation and vaccination. The current treatment for COVID19 is a bimodal therapy, one targets early infection and virus replication, and the other targets the systemic inflammatory phase of late infection and regulation [37], including host immune regulation, antiviral therapy, plasma therapy, anticoagulation therapy, ACE2 inhibitors, and steroid hormones. However, there is still no specific treatment, and "group immunity" cannot be achieved [22, 38-40]. Active symptom support is still the key for patients with mild to moderate disease, maintaining moisture and nutrition, and controlling fever and cough. Patients with severe infection or respiratory failure need to inhale oxygen through a face mask, high nasal 
flow, non-invasive ventilation, or mechanical ventilation. If all these prove ineffective, extracorporeal membrane oxygenation (ECMO) can be performed [41]. Currently, vaccination is the most promising preventive and treatment measure. In the 11 months since the SARS-CoV-2 and its genome were identified, the unremitting efforts of the scientific community have led to the development of more than 300 vaccine projects, and some vaccines have already been approved for emergency use. Available data indicate that new vaccine candidates might help protect individuals and reduce the spread of the pandemic [42].

\section{Emerging difficulties during the COVID-19 epidemic Sequelae of COVID-19}

At present, predicting the long-term effects of COVID19 , including the sequelae of the disease and the corresponding combined treatments, is still a challenge. The diverse presentations during the acute phase increase the difficulty in predicting the outcomes. Patients with severe diseases might suffer serious sequelae [43]. Studies have shown that more than three-quarters of COVID-19 patients report that they still have at least one symptom six months after the disease onset. The most commonly reported symptoms were fatigue or muscle weakness (63\%), sleep disorders (26\%), and anxiety or depression (23\%). The patients' lung function does not fully recover six months after the disease onset, and SARSCoV-2 might infect again [44]. During severe inflammation, the wound healing response goes through a scarring process called fibrosis, leading to permanent tissue and organ damage. Fibrosis is a pathological wound healing response that leads to significant remodeling of the extracellular environment. It primarily leads to a decrease in tissue elasticity, resulting in dysfunction of organs, such as the lungs and heart, that depend on elastic characteristics to maintain normal function. Similar to SARS and Middle East Respiratory Syndrome (MERS), evidence indicates that SARS-CoV-2 infection could cause fibrotic damage, leading to complications after the viral infection period [45]. The use of corticosteroids in critically ill patients with COVID-19 appears to reduce the 28-day all-cause mortality and should be used when needed [46]. However, high-dose corticosteroid use might cause longterm distress in the recipients. One study followed 71 SARS survivors for 15 years. All were treated with shortterm high-dose steroids at the severe stage of the disease. Of these, 15 cases of femoral head necrosis were considered to be related to steroid use, and four of them had mobility problems due to arthritis [47].

Chloroquine inhibits the production and release of tumor necrosis factor (TNF) and interleukin-6 (IL-6), suggesting that it could suppress the cytokine storm in COVID-19 patients [48]. However, current evidence failed to show the clinical benefits of prophylactic hydroxychloroquine over placebo or with no prevention, while the treatment shows a higher incidence of adverse events [49]. Hydroxychloroquine could cause neurological side effects, such as depression, psychosis, insomnia, manic episodes, and an increased risk of suicide [50, 51]. Treatment with it might weaken the host's immune response to SARS-CoV-2, especially in older patients or patients with comorbidities [52]. A study in Italy showed that the number of emergency room visits between February and April 2020 had decreased by $55 \%$, compared to 2019, due to COVID-19. This indirectly led to an increase in patients requiring intensive care. The incidences of atrial fibrillation, ischemic heart disease, and severe renal insufficiency were higher in 2020 [53].

\section{Mutation of SARS-CoV-2}

Many variants of SARS-CoV-2 have appeared. These mutations usually do not have a decisive effect on the biological behavior of the virus and do not make a significant change in its structure and composition [54]. Variant B.1.1.7 of SARS-CoV-2 appeared in the United Kingdom in September 2020 [55]. Kyodo News reported on January 31, 2021, that the three SARS-CoV-2 mutations found in the United Kingdom (B.1.1.7), South Africa (B.1.351), and Brazil (P.1) have spread to at least 77 countries and regions around the world. The spike $(\mathrm{S})$ protein of B.1.1.7 underwent a series of mutations, of which N501Y is one of the most important. The spike with this mutation binds more tightly to its cell receptor, ACE2 [56]. Current data indicate that B.1.1.7 does not escape the protection mediated by the Pfizer-BioNTech BNT162b2 COVID-19 vaccine [57]. After vaccination with the Moderna mRNA1273 COVID-19 vaccine, neutralization against the intact B.1.351 variant was reduced but was still significant [58]. Japan's National Institute of Infectious Diseases revealed that the existing vaccine is effective against B.1.1.7, but its effectiveness against the South African and Brazilian mutations is still unknown. Vaccine manufacturers suggest that they should improve the vaccines for the sake of prudence. The British pharmaceutical giant AstraZeneca stated that it has begun to improve its vaccine against the South African variant [59].

\section{The 'three syndromes and six Chinese patent medicines' project}

Based on previous experience during the SARS and MERS epidemics and the current understanding of COVID-19, we focused on the prevalent COVID-19 sequelae because there are currently more than 90 million infected patients, and most might be affected by these. Consequently, we initiated the "three syndromes 
and six Chinese patent medicines" study on sequelae during the recovery phase of COVID-19.

\section{The implementation process of the 'three syndromes and six Chinese patent medicines' project}

Academician Tong Xiaolin (XT) arrived in Wuhan on January 24, 2020. On January 29, XT proposed that the Wuchang District Government and Hubei Provincial Hospital of Traditional Chinese Medicine jointly carry out community prevention and control activity using Chinese medicine. It was suggested that full coverage of traditional Chinese medicine (TCM) would significantly reduce severe and critical illness and death. For the recovery period, the medical treatment team leader of the State Administration of Traditional Chinese Medicine and XT held a kick-off meeting for the "three syndromes and six Chinese patent medicines" project on April 10. At the kick-off meeting, XT proposed new use for established drugs. Six already marketed Chinese patent medicines were screened through a randomized, double-blind, placebo-controlled, multicenter clinical trial for treating three primary symptoms-cardiopulmonary function, sleep disturbance, and digestive function, during the recovery phase of COVID-19. The trials was completed on October 13, 2020 (Fig. 1; Table 1).

\section{Research of the three syndromes and six Chinese patent medicines \\ Treatment of abnormal cardiopulmonary function with traditional Chinese medicine}

Acute cardiovascular complications, such as acute coronary syndrome, myocarditis, arrhythmia, and heart failure, have been widely reported in COVID-19 patients [60]. In a meta-analysis, the prevalence of myocardial injury in COVID-19 patients was 5\%-38\% [61]. In an observational cohort of 100 patients who recovered from COVID-19, 78\% had abnormal cardiovascular magnetic resonance imaging 71 days after diagnosis. This

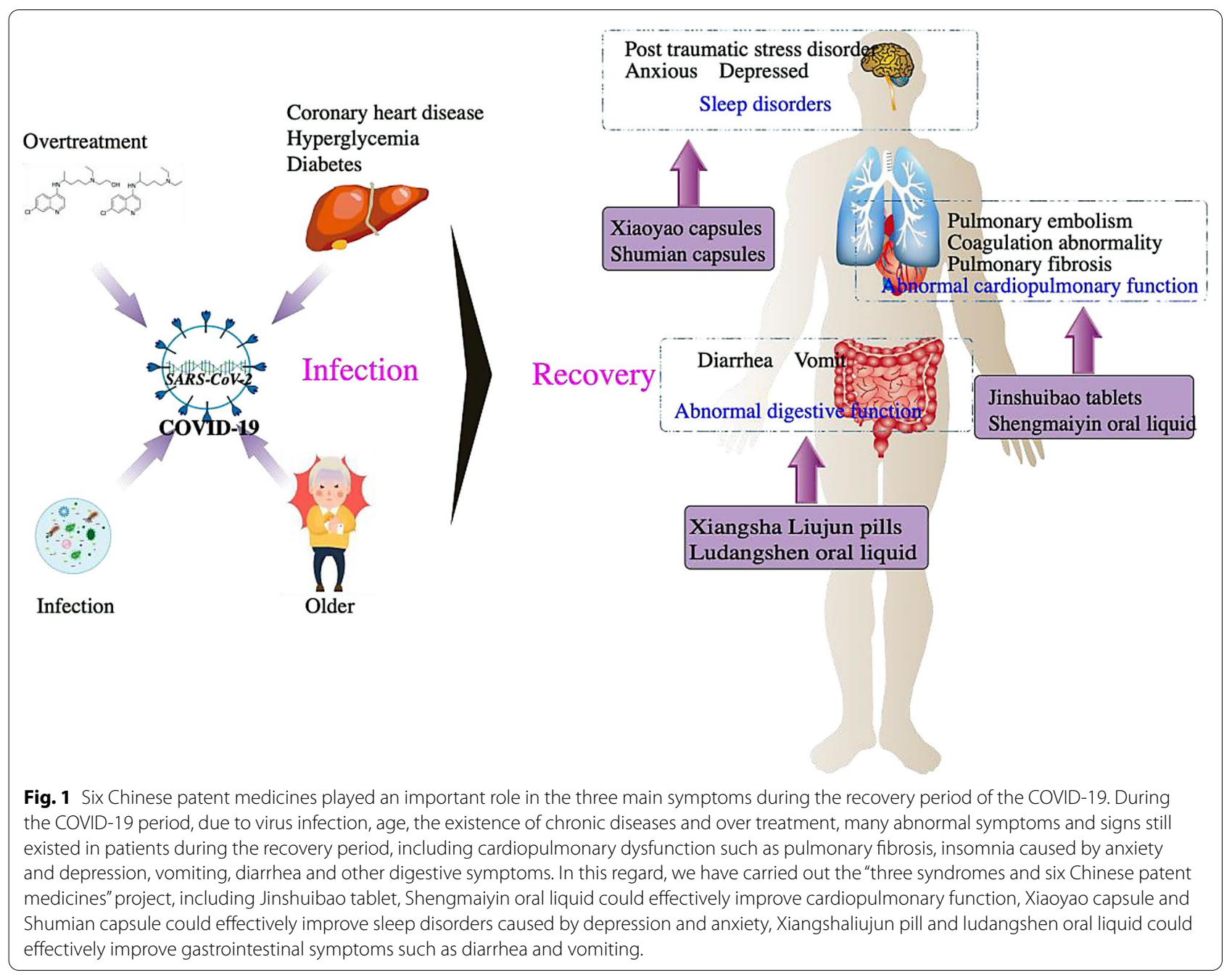




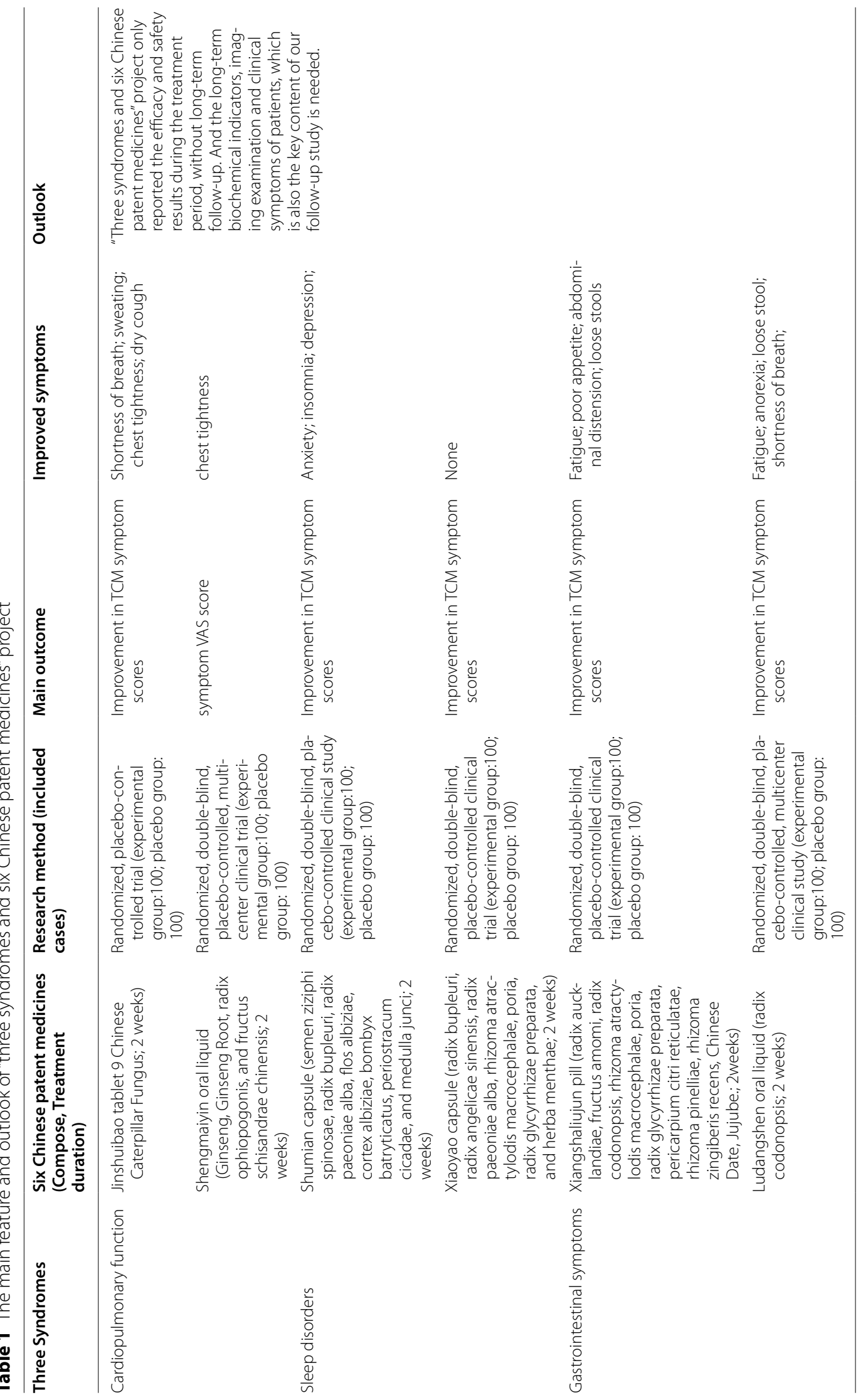


finding was unrelated to previous comorbidities and most patients possibly had pericardial myocarditis [62]. Many COVID-19 survivors also have pulmonary sequelae [63-65]. Similar to SARS and MERS, the most apparent acute complication described in the early stages of the COVID-19 pandemic was severe lung disease, which required a high mechanical ventilation rate [2]. Pulmonary embolism caused by SARS-CoV-2 aggravated the burden of COVID-19 respiratory system damage [27]. Lung expansion ability continued to be impaired in $52 \%$ of SARS patients two years after infection [66]. A prospective cohort study in Beijing followed 71 SARSinfected medical staff for 15 years, showing that their lung function continued to be slightly impaired [47]. A major retrospective study of 143 patients in Italy found that $87.4 \%$ of patients still had at least one symptom, such as dyspnea or fatigue, two months after recovering from acute SARS-CoV-2 infection [67].

The effect of Jinshuibao tablets on patients with abnormal cardiopulmonary function during the recovery from COVID-19 The prospective, randomized, placebocontrolled trial included patients who recovered from COVID-19 from Hubei Provincial Hospital of Traditional Chinese Medicine, Wuhan Seventh Hospital, and Wuhan First Hospital between April 27, 2020, and May 15, 2020. The inclusion criteria were: met the three symptoms of hospital cure for more than two weeks and had an impaired cardiopulmonary function, shortness of breath, sweating, dry cough, chest tightness, palpitation, and decreased pulmonary and heart function. The diagnostic criteria were based on the China 7th edition of the Diagnosis and Treatment of COVID-19 Guidelines. The Ethics Committee of Hubei Provincial Hospital of Traditional Chinese Medicine approved the research protocol (HBZY2020C27-01). Two-hundred patients were enrolled, 100 in the experimental group and 100 in the placebo group. The intervention measures were Jinshuibao tablets (fermented cordyceps powder, $0.33 \mathrm{~g} \times 63$ tablets/box). The patients received one tablet three times a day for two weeks, and the clinical outcomes were observed at 0,1 , and 2 weeks. Improvement in TCM symptom scores was compared between the two groups. The results showed that Jinshuibao tablets were better at reducing the symptom rates than the placebo, including shortness of breath $(21 / 98$ [21.43\%] vs. $8 / 96$ [8.83\%], $P=0.011)$, sweating $(29 / 78$ [37.18\%] vs. $15 / 74$ [20.27\%], $P=0.022)$, chest tightness (31/88 [35.23\%] vs. $14 / 91$ [15.38\%], $P=0.002)$, dry cough (30/51 [58.82\%] vs. $9 / 49$ [18.37\%], $P<0.001)$, and improve lung and heart function abnormalities.

Jinshuibao tablets are made of fermented Chinese Caterpillar Fungus powder that primarily contains nucleosides, bases, amino acids, sterols, and polysaccharides.
The polysaccharides mainly contain 11 monosaccharide components, such as mannose and glucosamine [68]. Clinical studies have shown that Jinshuibao tablets alone or when combined with tiotropium bromide inhalants could significantly improve lung dysfunction caused by obstructive pulmonary disease, including improving lung ventilation $[69,70]$, reducing airway obstruction to prevent bronchospasm [71], and improving the pulmonary fibrosis symptoms in animal models $[72,73]$. The medication might improve the patient's immune function by regulating peripheral blood Th17/Treg [70], significantly reducing the host's TNF- $\alpha$ and TGF- $\beta 1$ levels [74], and inhibiting the accumulation of inflammatory cells in the lungs [75].

Effect of treatment with Shengmaiyin oral liquid on patients with cardiopulmonary abnormalities during the recovery phase of COVID-19 The randomized, double-blind, placebo-controlled, multicenter clinical trial included 200 COVID-19 convalescent patients with cardiopulmonary symptoms from Wuhan First Hospital, Wuhan Seventh Hospital, and Xiaogan Traditional Chinese Medicine Hospital from April 27, 2020, to May 14, 2020. All COVID-19 recovering patients were diagnosed and classified following the China 7th edition of the COVID-19 Diagnosis and Treatment Guidelines. The research plan was reviewed by the Ethics Committee of Wuhan First Hospital. The criteria for recovery were at least $72 \mathrm{~h}$ without fever, chest computed tomography $(\mathrm{CT})$ showing substantial improvement in both lungs, clinical relief of respiratory symptoms, and two negative SARSCoV-2 RNA pharynx tests obtained at least $24 \mathrm{~h}$ apart. Inclusion criteria were: aged 18-70 years, 2-4 weeks after discharge, and diagnosis of cardiopulmonary insufficiency, with two to three of the following clinical symptoms: shortness of breath, hyperhidrosis, chest tightness, palpitations, dry cough, or symptoms with a visual analog scale (VAS) score $>4$. All participants signed informed consent forms. The intervention measures were Shengmai oral liquid that contained ginseng, Ophiopogon japonicus, and Schisandra (Tongrentang (Beijing) Co., Ltd., Beijing, China; National Drug Approval No. Z11020372). The patients received $10 \mathrm{~mL}$ of the fomulation three times a day for 2 weeks. The placebo group received a comforting agent following the same regimen. The cure standard was a symptom VAS score of zero after treatment. If the symptom VAS score decreased by $30 \%$ or more after treatment, the intervention was considered effective. Of the 200 patients, 192 completed the clinical observations. The results showed that the 2-week treatment with Shengmai oral liquid improved the chest tightness symptoms more than the placebo $(75.00 \%$ vs. $55.56 \%, P<0.05)$. The study also showed that Shengmai oral liquid effectively 
improved lung and heart function and the quality of life of patients recovering from COVID-19.

Twenty one Compounds of Shengmaiyin include 14 saponins, 6 lignans [76]. It is often used to treat chronic obstructive pulmonary disease [77], diabetic myocardium disease [78], and coronary atherosclerotic heart disease [79]. It exerts its action primarily by improving mitochondrial lipid metabolism and inhibiting oxidative stress damage [80]. Research on ginseng has mainly focused on saponins, polysaccharides, and volatile components. Among them, ginsenoside Rg1, the main component of ginseng, was shown to regulate various cell signaling pathways, including the c-Jun $\mathrm{N}$-terminal kinase (JNK) pathway [81, 82], thus protecting the heart from various cardiovascular diseases. For example, it inhibits endoplasmic reticulum stress and autophagy to improve cardiac dysfunction caused by adriamycin [83]. Ginsenoside Re negatively affects cardiac contractility and autonomy and can cause changes in cardiac electrophysiological characteristics, which might be the reason for its antiarrhythmic effects [84]. Ginsenoside Rg1 effectively alleviated lung injury caused by sepsis, primarily by upregulating SIRT1 to alleviate endoplasmic reticulum stress and inflammation [85]. The main components of O. japonicus include steroidal saponins, high isoflavones, and polysaccharides, with various pharmacological activities, including anti-inflammatory and immune regulatory [86]. Three new isoflavone compounds isolated from the roots of $O$. japonicus were shown to alleviate the release of inflammatory chemokines in allergic bronchial asthma [87]. Schisandra is usually used to treat chronic cough. Its ethanol extract has a significant antitussive effect. It contains schisandrin and deoxyschisandrin, and it significantly weakens lung neutrophils and total inflammatory cells and increases the infiltration of TNF- $\alpha$ and interleukin-8 (IL-8) in the lungs [88]. Schisandra can also change the antioxidant status of the heart and improve its function [89].

\section{Treatment of sleep disorders with traditional Chinese medicine}

Previous evidence showed that some SARS patients have long-term psychological or memory abnormalities [90]. For example, in a cohort study of 99 SARS survivors, $33.5 \%$ were diagnosed with mental illness 30 months after infection, even though only $6 \%$ had a history of mental illness before SARS infection [91]. A meta-analysis of patients infected with SARS or MERS showed that $39 \%$ of them had post-traumatic stress disorder (PTSD), and 30-33\% suffered from anxiety and depression [92]. The COVID-19 outbreak has affected physical health [93], and has induced a global mental health crisis, including mental illness and suicide [94-96].
Acute neuropsychiatric symptoms have been reported in $40-88 \%$ of patients with severe acute COVID-19 [97]. In a UK surveillance study of 125 unique COVID19 cases, 77 experienced cerebrovascular events, and 39 had altered mental status [91]. In another study on 1,172 COVID-19 respondents recruited from 125 cities in China, anxiety and insomnia occurred in $33.02 \%$ and 24.66\%, respectively. During the COVID-19 outbreak, physical and psychological symptoms are common in the general population [98]. The severity of insomnia was related to symptoms of depression and anxiety [99]. Research conducted during the initial stage of COVID-19 had highlighted its impact on mental health, with many people showing anxiety and depression [100, 101], facing the risk of post-traumatic stress disorder [102].

Effect of Shumian capsules on patients with sleep disorders during the recovery phase of COVID-19 The randomized, double-blind, placebo-controlled clinical study included 200 COVID-19 patients with sleep and emotional disorders in Hubei Provincial Hospital of Traditional Chinese Medicine from April to May 2020. Recovery of the COVID-19 patients was determined following the 7th edition of COVID-19 Diagnosis and Treatment Guidelines. The Ethics Committee of Hubei Hospital of Traditional Chinese Medicine examined and approved this study (No. HBZY2020-C27-01). Inclusion criteria were: meeting the diagnostic criteria for COVID-19 rehabilitation, cured and discharge for more than two weeks, and age between 18 to 70 . All participants had sleep disorders, such as irritability, anxiety, or poor sleep, as the main clinical manifestations, with two symptoms appearing simultaneously or a single symptom graded as VAS $\geq 4$, and all signed informed consent forms. The intervention was Shumian 0.4-g capsules (approval number: Z20050543), given orally, three tablets/capsules twice a day for two weeks. The control group received an equal dose of a placebo. The results showed that the anxiety symptom score of the experimental group after one week of treatment was significantly lower than the control group $(3.00 \pm 2.15$ vs. $4.00 \pm 2.06, P<0.05)$. After two weeks of treatment, the treatment effectivity rate for insomnia (67/96 [69.79\%] vs. 45/86 [52.33\%], $P=0.004)$, anxiety (53/82 [64.63\%] vs. $35 / 79$ [44.30\%], $P=0.006)$, and depression (43/66 [65.15\%] vs. 26/65 [40.00\%], $P=0.002)$ was higher in the experimental group than in the control group. Studies have shown that Shumian capsules significantly improved sleep and mood disorders due to COVID-19 during the recovery phase.

Shumian capsules are composed of SEMEN ZIZIPHI SPINOSAE, RADIX BUPLEURI, RADIX PAEONIAE ALBA, FLOS ALBIZIAE, CORTEX ALBIZIAE, BOMBYX BATRYTICATUS, PERIOSTRACUM CICADAE, and 
MEDULLA JUNCI. Jujube seed water extract can reduce insomnia symptoms by regulating the levels of monoamine and amino acid neurotransmitters in the brain [103]. Jujube is an effective ingredient in jujube seeds, which can enhance the hypnotic effect of pentobarbital and increase the sleeping time [104]. The Bupleurum formula is widely used to treat major depression [105]; it can improve the behavior of depression by regulating the metabolic profile and intestinal flora [106]. The active ingredient of Radix Paeoniae Alba has obvious antidepressant-like effects, which are closely related to the increase in hippocampal serotonin/adrenaline and the expression of brain-derived neurotrophic factor [107]. Bupleurum and Radix Paeoniae Rubra are among the most popular herbal pairs prescribed in TCM to treat depression. In animal models, the antidepressant effects of Radix Paeoniae Rubra and Radix Paeoniae Rubra were significantly better than those of Radix Paeoniae Rubra or Radix Paeoniae Rubra, achieved by regulating the mitogen-activated protein kinase (MAPK) signaling pathway. This conduction pathway and arachidonic acid metabolism have a synergistic effect [108]. Pretreatment with Bupleurum and Radix Paeoniae Alba significantly increased the concentration of serotonin and epinephrine in the hippocampus and cortical tissue [109]. A. julibrissin is used as a sedative in traditional oriental medicine. The flavonol glycosides quercitrin and isoquercitrin isolated from A. julibrissin increased sleeping time for pentobarbital-induced mice in a dose-dependent manner [110]. The anti-anxietylike effects of $A$. julibrissin water extract are mediated by changes in the serotonergic nervous system, especially 5-HT1A receptors [111]. Stiff silkworms contain various chemical components, particularly proteins, peptides, and amino acids [112]. Its water-extract and alcoholprecipitate can effectively reduce the autonomous activities of mice and have sedative and hypnotic effects [113]. Cicada slough contains 17 hydrolyzed amino acids and various trace elements [114, 115]. Extracts with cicada slough, ethanol, and water showed anticonvulsant effects on pentylenetetrazol-induced convulsions in mice. The direct inhibitory effect of the water extracts was significant [116]. Rushes include luteolin, eriochlor, and vanillic acid [117]. Phenanthrene is the main effective component of Juncus serrata anti-anxiety effect [118], while the sedative and hypnotic effects of rushes ethyl acetate extract are the most obvious [119].

Effect of Xiaoyao capsules on patients with sleep disturbance during the recovery period from COVID-19 This randomized, double-blind, placebo-controlled clinical trial included 200 patients with sleep and mood disorders during their recovery from COVID-19, as defined in the 7th edition of the COVID-19 Diagnosis and Treatment
Guidelines. Patients were recruited from April 1, 2020, to June 1,2020 . The inclusion criteria were: patients meeting the diagnostic criteria for the recovery phase of COVID19 that were discharged from hospital for at least two weeks, had 2-3 symptoms of sleep or mood disorders, or a single symptom with a VAS score $>4$, age $18-70$ years. All participants provided written informed consent. Patients in the treatment group orally received four Xiaoyao capsules (0.34 g/capsule, China National Medical Products Administration approval no.: Z20050543) twice daily for two weeks. Patients in the control group received orally four Xiaoyao simulant capsules $(0.34 \mathrm{~g}$; placebo) twice daily for two weeks. Two weeks of Xiaoyao capsule treatment did not improve the symptom score over the control for irritability $(4.43 \pm 2.21$ vs. $4.37 \pm 2.11, P=0.842)$, anxiety $(4.93 \pm 1.83$ vs. $4.56 \pm 1.74, P=0.147)$, and poor sleep $(5.53 \pm 1.71$ vs. $5.04 \pm 1.66, P=0.044)$. This study shows that Xiaoyao capsules cannot significantly improve the clinical symptoms of sleep and mood disorders during recovery from COVID-19.

Xiaoyao capsules are composed of radix bupleuri, radix angelicae sinensis, radix paeoniae alba, rhizoma atractylodis macrocephalae, poria, radix glycyrrhizae preparata, and herba menthae. Xiaoyao helps to soothe the liver and strengthening the spleen, nourishing blood, and regulating menstruation. It is often used clinically to treat sleep disorders caused by liver qi stagnation. Sleep disorders in this study patients were caused primarily by anxiety and irritability. This could explain why the Xiaoyao capsules failed to improve sleep and mood disorders in COVID-19 patients during the recovery phase.

\section{Treatment of abnormal digestive function with traditional Chinese medicine}

After SARS-CoV-2 infects the lung cells, the effector $\mathrm{CD} 4+\mathrm{T}$ cells reach the small intestine following the intestine-lung axis, causing some gastrointestinal symptoms [11], including diarrhea (3.8\%) and vomiting (5.0\%) $[30,31]$. Spleen and stomach dysfunctions are present in many COVID-19 convalescent patients. Approximately $5 \%$ of patients have abnormal digestive functions, including diarrhea or vomiting [44].

Effect of Xiangsha Liujun pills on patients with abnormal digestive function during the recovery period from COVID-19 This randomized, double-blind, placebo-controlled clinical trial recruited 200 patients with reduced digestive system function, including fatigue, loss of appetite, abdominal distension, and loose stool. All patients were in Hubei Province and during the recovery phase of COVID-19 as defined in the 7th edition of the COVID-19 Diagnosis and Treatment Guidelines. The inclusion criteria were: meeting the criteria for the 
recovery phase of COVID-19, cured and discharged from hospital for at least 2 weeks, aged $18-70$ years. The main clinical manifestations were decreased digestive function symptoms such as fatigue, poor appetite, abdominal distension, and loose stools. Included patients had simultaneously at least three of these symptoms or had a single symptom with a VAS $>4$. All participants signed informed consent forms. Patients in the experimental group were orally administered with Xiangsha Liujun pills, 12 pills three times a day for two weeks, half an hour before each meal. Eight pills contained the equivalent of $3 \mathrm{~g}$ of the original medicine. The control group received a placebo as prescribed by the physician, taken orally, one packet three times a day for two weeks, half an hour before each meal. Xiangsha Liujun Wan (concentrated pill; Zhongjing Wanxi Pharmaceutical Co., Ltd.; batch number: 200203). The results showed that providing Xiangsha Liujun pills as treatment for two weeks of significantly improved the symptoms of fatigue (70/80 [87.50\%] vs. $58 / 83$ [69.88\%], $P=0.006)$, poor appetite $(72 / 75(96.00 \%)$ vs. $62 / 80$ (77.50\%), $P<0.001)$, abdominal distension (81/90 [90.00\%] vs. 52/88 [59.09\%], $P<0.001)$, and loose stools (37/40 (92.50\%) vs. $25 / 52$ (48.08\%), $P<0.001)$.

Xiangsha Liujun pills are composed of radix aucklandiae, fructus amomi, radix codonopsis, rhizoma atractylodis macrocephalae, poria, radix glycyrrhizae preparata, pericarpium citri reticulatae, rhizoma pinelliae, rhizoma zingiberis recens, Chinese Date, Jujube. The chemical components of woody plants are mainly terpenes, alkaloids, anthraquinones, and flavonoids [120]. Muxiang decoction can accelerate gastric emptying and enhance the release of motilin [121]. Animal experiments have shown that different doses of the Muxiang decoction can promote gastric emptying and intestinal propulsion [122]. Brain-simmered woody can prevent diarrhea by maintaining the osmotic pressure and volume inside and outside the cells and the normal irritability of muscle nerves, and reducing the gastrointestinal tract excitability [123]. Amomum villosum contains as many as 138 chemical components, including bornyl acetate and camphor $[124,125]$. A. villosum has a certain therapeutic effect on rats with functional dyspepsia and can promote gastric emptying and the release of substance $P$ and motilin in gastric antrum tissue [126, 127]. Codonopsis contains sterols, glycosides, alkaloids, nitrogen-containing components, volatile oil, and a variety of inorganic elements and amino acids necessary for the human body [128]. The inulin-type fructan CP-A isolated from Codonopsis pilosula can significantly improve gastric mucosal injury, high ulcer index, and gastric mucosal bleeding injury in rats with acute gastric ulcers induced by ethanol [129]. C. pilosula water extract enhances the small intestine propulsion rate and serum motilin level in mice [130], an excitatory gastrointestinal hormone [131, 132]. C. pilosula polysaccharide treatment in rats can increase their appetite and food intake, and stomach pepsin excretion and activity [133]. The active ingredients of Atractylodes macrocephala include lactones, glycosides, polysaccharides, and amino acids [134]. Studies have shown that Baizhu promotes the proliferation of the beneficial bacteria Bifidobacterium and Lactobacillus in the intestinal flora and improves the intestinal flora status [135]. Atractylodes I has a strong role in enhancing salivary amylase activity, promoting intestinal absorption, and regulating intestinal function [136]. Atractylodes macrocephala stimulates the myoelectricity of the smooth muscle of the small intestine by exciting the $\mathrm{M}$ receptors of the gastrointestinal tract, thereby promoting gastrointestinal movement [137]. The main chemical components of Poria are triterpenoids and polysaccharides [138]. Poria decoction can directly relax isolated rabbit intestinal muscles and reduce the intestinal muscle contraction amplitude; it can prevent experimental gastric ulcers in rats and inhibit gastric juice secretion [139]. The main active ingredients of licorice extract include glycyrrhizin and glycyrrhetinic acid [140]. The decoction of raw licorice could reduce the tension of the spontaneous contraction of the intestine and could be used as a potentially therapeutic substance to improve gastrointestinal dysfunction [141]. The ethyl acetate extract of dried tangerine peel decoction is the strongest part of the digestion-promoting activity [142], and tangeretin and hesperetin can significantly promote the excretion of gastric juice and pepsin, improve the activity of pepsin, and enhance digestive function [143]. Pinellia is composed primarily of alkaloids and sterols [144]. The decoction and alcohol precipitation of Pinellia can inhibit gastric juice secretion in rats, reduce the free and total acids in the gastric juice, inhibit pepsin activity, protect the gastric mucosa, and promote mucosal regeneration [145]. Ginger contains many active substances, such as ginger essential oils, polysaccharides, sterols, and curcumin [146]. Curcumin significantly improved the activity of digestive enzymes in the small intestine of mice and promoted digestion. Additionally, it had a protective effect against gastric mucosal stimulation and chemical damage [147]. For example, ginger powder can significantly improve gastric mucosal damage caused by aspirin and has a protective effect on the gastric mucosa [148]. Jujube contains triterpenes, saponins, alkaloids, flavonoids, and glycosides [149]. Jujube polysaccharides, including glucose and fructose, can effectively reduce intestinal peristalsis time and contact with toxic and other harmful substances [150] and effectively treat constipation [151]. 
Effect of Ludangshen oral liquid on patients with abnormal digestive function during the recovery phase of COVID-19 The randomized, double-blind, placebocontrolled, multicenter clinical study recruited 200 patients at the recovery phase of COVID-19 following the 7th edition of the COVID-19 Diagnosis and Treatment Guidelines. Patients were treated at the Hubei Provincial Hospital of Traditional Chinese Medicine, Ezhou Traditional Chinese Medicine Hospital, and Xiaogan Traditional Chinese Medicine Hospital and had an abnormal digestive function. The Ethics Committee of Hubei Hospital for Traditional Chinese Medicine approved the trial (HBZY2020-C01-01). The inclusion criteria were as follows: meeting the diagnostic criteria of the COVID-19 recovery phase; at least two or three of the following TCM symptoms: fatigue, anorexia, diarrhea, loose stools, shortness of breath, and other symptoms related to decreased digestive function, or a single symptom with VAS score $>4$; discharged from hospital for two to four weeks; aged 18 to 70 years; provided written informed consent. Patients in the intervention group were treated with Ludangshen oral solution (Shanxi Zhenglai Pharmaceutical Co., Ltd., Shanxi, China, production batch No. Z20059002), $10 \mathrm{~mL}$ twice daily for two weeks. Patients in the control group were treated with a placebo of Ludangshen oral solution (Shanxi Zhenglai Pharmaceutical Co., Ltd.), $10 \mathrm{~mL}$ twice daily for two weeks. The Ludangshen oral and placebo solutions were indistinguishable in flavor, taste, and appearance, including packaging color. Patients with comorbidities were allowed to undergo corresponding treatments. After two weeks of treatment, the symptom scores of fatigue $(1.28 \pm 1.45$ vs. $3.01 \pm 1.97, P<0.001)$, anorexia $(0.53 \pm 1.08$ vs. $1.49 \pm 1.76, P<0.001)$, loose stool $(0.51 \pm 1.44$ vs. $1.19 \pm 2.04, P=0.009)$, and shortness of breath $(0.89 \pm 1.33$ vs. $1.68 \pm 2.22, P=0.003)$ in the Ludangshen group were significantly lower than in the placebo group. Ludangshen oral liquid could be used as an optional treatment of abnormal digestive function in COVID-19 patients during the recovery phase.

As mentioned earlier, Codonopsis can effectively protect the gastrointestinal tract. Pharmacokinetic experiments showed that Lu Codonopsis increases the appetite [152]. Codonopsis regulation of the gastrointestinal function might be related to improvement in gastrointestinal motility and pepsin activity. The water extract of Codonopsis was reported to enhance the intestinal propulsion rate and serum motilin levels in mice [130].

\section{Outlook}

At present, there are a large number of COVID-19 patients, more than 93 million confirmed infections. No matter in the COVID-19 infection stage or recovery stage, many high-quality studies had shown that the effect of traditional Chinese medicine is significant, and now there is a complete evidence chain $[153,154]$ about the prevention, treatment and recovery period of traditional Chinese medicine for COVID-19 [153, 154], that is, the role of traditional Chinese medicine is self-evident, and there are a large number of patients in recovery period in many regions, so more patients need to participate in the use of traditional Chinese medicine.

Previous studies on SARS suggested that the post infection effect of the virus would last for a long time. Our study of "three syndromes and six Chinese patent medicines" project only reported the efficacy and safety results during the treatment period, without long-term followup. We would track the biochemical indicators, imaging examination and clinical symptoms of patients, which is also the key content of our follow-up study.

\section{Conclusion}

Many patients are presently recovering from COVID-19. Studies have shown that over three-quarters of COVID19 patients report at least one symptom six months after the disease onset [44]. Fibrotic injury caused by SARS-CoV-2 could also lead to other complications [45]. Medications used during COVID-19 treatment, such as high-dose corticosteroids, might have long-term consequences, such as femoral head necrosis, arthritis, and inconvenience [47]. XT took the lead in launching the "three syndromes and six Chinese patent medicines" project on April 10, 2020, that screened six existing listed drugs through randomized, double-blind, placebocontrolled, multicenter clinical trials to treat symptoms of cardiopulmonary function, sleep disorder, and digestive function during the COVID-19 recovery phase. The results showed that Jinshuibao tablets and Shengmaiyin oral liquid significantly improved the patients' cardiopulmonary function. Shumian capsules significantly improved the patients' sleep disorders. Xiaoyao capsules wre ineffective for this indication, possibly because the cause, in this case, was liver Qi stagnation, not psychological or emotional disorders. Xiangsha Liujun pills and Ludangshen oral liquid significantly improved the patients' digestive function. Our research provides a selection of treatment measures for disease sequelae in patients during the COVID-19 recovery phase based on high-quality evidence.

\footnotetext{
Abbreviations

COVID-19: Coronavirus disease 2019; SARS-CoV-2: Severe acute respiratory syndrome coronavirus-2; WHO: World Health Organization; ARDS: Acute respiratory distress syndrome; ACE2: Angiotensin-converting enzyme II; IL-1B: Interleukin 1-B; IFN- $\gamma$ : Interferon- $\gamma$; IP-10: Chemokine-10; MCP-1: Monocyte chemoattractant protein 1; RT-PCR: Reverse transcription-polymerase chain reaction; ECMO: Extracorporeal membrane oxygenation; MERS: Middle east respiratory syndrome; TNF: Tumor necrosis factor; IL-6: Interleukin-6; XT: Tong
} 
Xiaolin; TCM: Traditional Chinese medicine; CT: Computed tomography; VAS: Visual analog scale; JNK: C-Jun N-terminal kinase; IL-8: Interleukin-8; PTSD: Post-traumatic stress disorder; MAPK: Mitogen-activated protein kinase.

\section{Acknowledgements}

Not applicable.

\section{Authors' contributions}

$F L$ and $X T$ designed the protocols; LD, DJ, RZ, SZ, and YD searched the related literature; FL, XA, and YZ drafted the manuscript. All authors read and approved the final manuscript.

\section{Funding}

This work was supported by the National Key R\&D Program (2020YFC0845000) and the State Administration of Traditional Chinese Medicine Special Project of Chinese Medicine Emergency Response to New Coronavirus Pneumonia (2020ZYLCYJ04-1). The funders had no role in the study design, data collection, analysis, and interpretation, in writing the report, or in the decision to submit the article for publication.

\section{Availability of data and materials}

Not applicable.

\section{Declarations}

\section{Ethics approval and consent to participate}

Not applicable.

\section{Consent for publication}

Yes.

\section{Competing interests}

None.

\section{Author details}

'Department of Endocrinology, Guang'anmen Hospital, China Academy of Chinese Medical Sciences, Beijing 100053, China. ${ }^{2}$ China Academy of Chinese Medical Sciences, Beijing 100700, China. ${ }^{3}$ Beijing University of Chinese Medicine, Beijing 100029, China.

Received: 30 March 2021 Accepted: 31 May 2021

Published online: 07 June 2021

\section{References}

1. John Hopkins University (2020) COVID-19 Dashboard by the Center for Systems Science and Engineering (CSSE) at Johns Hopkins University (JHU). https://www.coronavirus.jhu.edu/map.html. Accessed 15 Jan 2020.

2. Wang D, Hu B, Hu C, Zhu F, Liu X, Zhang J, et al. Clinical characteristics of 138 hospitalized patients with 2019 novel coronavirus-infected pneumonia in Wuhan, China. JAMA. 2020;323(11):1061-9.

3. Li J, He X, Yuan Y, Zhang W, Li X, Zhang Y, et al. Meta-analysis investigating the relationship between clinical features, outcomes, and severity of severe acute respiratory syndrome coronavirus 2 (SARS-CoV-2) pneumonia. Am J Infect Control. 2021:49:82-9.

4. Mason RJ. Pathogenesis of COVID-19 from a cell biology perspective. Eur Respir J. 2020;55(4):2000607.

5. Chen L, Sun W, Liu Y, Zhang L, Lv Y, Wang Q, et al. Association of earlyphase in-hospital glycemic fluctuation with mortality in adult patients with coronavirus disease 2019. Diabetes Care. 2021;44:865-73.

6. Li B, Yang J, Zhao F, Zhi L, Wang X, Liu L, et al. Prevalence and impact of cardiovascular metabolic diseases on COVID-19 in China. Clin Res Cardiol. 2020;109(5):531-8.

7. Zhou F, Yu T, Du R, Fan G, Liu Y, Liu Z, et al. Clinical course and risk factors for mortality of adult inpatients with COVID-19 in Wuhan, China: a retrospective cohort study. Lancet. 2020;395(10229):1054-62.

8. The Novel Coronavirus Pneumonia Emergency Response Epidemiology Team. The epidemiological characteristics of an outbreak of 2019 novel coronavirus diseases (COVID-19)—China, 2020. China CDC Weekly. 2020;2:113-22.

9. Lu R, Zhao X, Li J, Niu P, Yang B, Wu H, et al. Genomic characterisation and epidemiology of 2019 novel coronavirus: implications for virus origins and receptor binding. Lancet. 2020;395(10224):565-74.

10. Zhou P, Shi ZL. SARS-CoV-2 spillover events. Science. 2021;371(6525):120-2.

11. Ye Q, Wang B, Zhang T, Xu J, Shang S. The mechanism and treatment of gastrointestinal symptoms in patients with COVID-19. Am J Physiol Gastrointest Liver Physiol. 2020;319(2):G245-52.

12. Elbadawy HM, Khattab A, Alalawi A, Aljohani F, Sundogji H, Mahmoud AS, et al. The detection of SRAS-CoV-2 in outpatient clinics and public facilities during the COVID19 pandemic. J Med Virol. 2021;93:29955-32961.

13. Zu ZY, Jiang MD, Xu PP, Chen W, Ni QQ, Lu GM, et al. Coronavirus disease 2019 (COVID-19): a perspective from China. Radiology. 2020;296(2):E15-e25.

14. Wan Y, Shang J, Graham R, Baric RS, Li F. Receptor recognition by the novel coronavirus from wuhan: an analysis based on decade-long structural studies of SARS coronavirus. J Virol. 2020;94(7).

15. Nie X, Qian L, Sun R, Huang B, Dong X, Xiao Q, et al. Multi-organ proteomic landscape of COVID-19 autopsies. Cell. 2021;184:775-91.

16. Huang C, Wang Y, Li X, Ren L, Zhao J, Hu Y, et al. Clinical features of patients infected with 2019 novel coronavirus in Wuhan, China. Lancet. 2020;395(10223):497-506.

17. Pence BD. Severe COVID-19 and aging: are monocytes the key? Geroscience. 2020:42(4):1051-61

18. Chousterman BG, Swirski FK, Weber GF. Cytokine storm and sepsis disease pathogenesis. Semin Immunopathol. 2017;39(5):517-28.

19. Ye Q, Wang B, Mao J. The pathogenesis and treatment of the 'Cytokine Storm' in COVID-19. J Infect. 2020;80(6):607-13.

20. Cattaneo M, Bertinato EM, Birocchi S, Brizio C, Malavolta D, Manzoni $M$, et al. Pulmonary embolism or pulmonary thrombosis in COVID19 ? Is the recommendation to use high-dose heparin for thromboprophylaxis justified? Thromb Haemost. 2020;120(8):1230-2.

21. Ackermann M, Verleden SE, Kuehnel M, Haverich A, Welte T, Laenger $F$, et al. Pulmonary vascular endothelialitis, thrombosis, and angiogenesis in Covid-19. N Engl J Med. 2020;383(2):120-8.

22. Page EM, Ariens RAS. Mechanisms of thrombosis and cardiovascular complications in COVID-19. Thromb Res. 2021:200:1-8.

23. Kommoss FKF, Schwab C, Tavernar L, Schreck J, Wagner WL, Merle U, et al. The pathology of severe COVID-19-related lung damage. Dtsch Arztebl Int. 2020;117(29-30):500-6.

24. Chen Z, Hu J, Liu L, Zhang Y, Liu D, Xiong M, et al. Clinical characteristics of patients with severe and critical COVID-19 in Wuhan: a single-center, retrospective study. Infect Dis Ther. 2021.

25. Spiezia L, Boscolo A, Poletto F, Cerruti L, Tiberio I, Campello E, et al. COVID-19-related severe hypercoagulability in patients admitted to intensive care unit for acute respiratory failure. Thromb Haemost. 2020;120(6):998-1000.

26. Zhai Z, Li C, Chen Y, Gerotziafas G, Zhang Z, Wan J, et al. Prevention and treatment of venous thromboembolism associated with coronavirus disease 2019 infection: a consensus statement before guidelines. Thromb Haemost. 2020;120(6):937-48.

27. Klok FA, Kruip M, van der Meer NJM, Arbous MS, Gommers D, Kant $\mathrm{KM}$, et al. Incidence of thrombotic complications in critically ill ICU patients with COVID-19. Thromb Res. 2020;191:145-7.

28. Haimei MA. Pathogenesis and treatment strategies of COVID19-related hypercoagulant and thrombotic complications. Clin Appl Thromb Hemost. 2020;26:1076029620944497.

29. Lillicrap D. Disseminated intravascular coagulation in patients with 2019-nCoV pneumonia. J Thromb Haemost. 2020;18(4):786-7.

30. Guan WJ, Ni ZY, Hu Y, Liang WH, Ou CQ, He JX, et al. Clinical characteristics of coronavirus disease 2019 in China. N Engl J Med. 2020;382(18):1708-20.

31. Gao QY, Chen YX, Fang JY. 2019 Novel coronavirus infection and gastrointestinal tract. J Dig Dis. 2020;21(3):125-6.

32. Rhea EM, Logsdon AF, Hansen KM, Williams LM, Reed MJ, Baumann KK, et al. The S1 protein of SARS-CoV-2 crosses the blood-brain barrier in mice. Nat Neurosci. 2020;24:368-78. 
33. Chen N, Zhou M, Dong X, Qu J, Gong F, Han Y, et al. Epidemiological and clinical characteristics of 99 cases of 2019 novel coronavirus pneumonia in Wuhan, China: a descriptive study. Lancet. 2020;395(10223):507-13.

34. An update on the epidemiological characteristics of novel coronavirus pneumonia (COVID-19). Zhonghua Liu Xing Bing Xue Za Zhi. 2020;41(2):139-44.

35. Eftekhari A, Alipour M, Chodari L, Maleki Dizaj S, Ardalan M, Samiei M, et al. A comprehensive review of detection methods for SARS-CoV-2. Microorganisms. 2021;9(2):232.

36. Ediz Tutuncu E, Ozgur D, Karamese M. Saliva samples for detection of SARS-CoV-2 in mildly symptomatic and asymptomatic patients. J Med Virol. 2021.

37. Zhu H, Rhee JW, Cheng P, Waliany S, Chang A, Witteles RM, et al. Cardiovascular complications in patients with COVID-19: consequences of viral toxicities and host immune response. Curr Cardiol Rep. 2020;22(5):32.

38. Arabi YM, Mandourah Y, Al-Hameed F, Sindi AA, Almekhlafi GA, Hussein MA, et al. Corticosteroid therapy for critically ill patients with middle east respiratory syndrome. Am J Respir Crit Care Med. 2018;197(6):757-67.

39. Shang L, Zhao J, Hu Y, Du R, Cao B. On the use of corticosteroids for 2019-nCoV pneumonia. Lancet. 2020;395(10225):683-4.

40. Ganesh B, Rajakumar T, Malathi M, Manikandan N, Nagaraj J, Santhakumar A, et al. Epidemiology and pathobiology of SARS-CoV-2 (COVID-19) in comparison with SARS, MERS: an updated overview of current knowledge and future perspectives. Clin Epidemiol Glob Health. 2021;10:100694.

41. Li Z, Yi Y, Luo X, Xiong N, Liu Y, Li S, et al. Development and clinical application of a rapid IgM-lgG combined antibody test for SARS-CoV-2 infection diagnosis. J Med Virol. 2020;92(9):1518-24

42. Forni G, Mantovani A. COVID-19 vaccines: where we stand and challenges ahead. Cell Death Differ. 2021;28:626-39.

43. Wiersinga WJ, Rhodes A, Cheng AC, Peacock SJ, Prescott HC. Pathophysiology, transmission, diagnosis, and treatment of coronavirus disease 2019 (COVID-19): a review. JAMA. 2020;324(8):782-93.

44. Huang C, Huang L, Wang Y, Li X, Ren L, Gu X, et al. 6-month consequences of COVID-19 in patients discharged from hospital: a cohort study. Lancet. 2021;397(10270):220-32.

45. George PM, Wells AU, Jenkins RG. Pulmonary fibrosis and COVID19: the potential role for antifibrotic therapy. Lancet Respir Med. 2020;8(8):807-15.

46. Sterne JAC, Murthy S, Diaz JV, Slutsky AS, Villar J, Angus DC, et al. Association between administration of systemic corticosteroids and mortality among critically ill patients with COVID-19: a meta-analysis. JAMA. 2020;324(13):1330-41.

47. Zhang P, Li J, Liu H, Han N, Ju J, Kou Y, et al. Long-term bone and lung consequences associated with hospital-acquired severe acute respiratory syndrome: a 15-year follow-up from a prospective cohort study. Bone Res. 2020;8:8.

48. Gao J, Tian Z, Yang X. Breakthrough: chloroquine phosphate has shown apparent efficacy in treatment of COVID-19 associated pneumonia in clinical studies. Biosci Trends. 2020;14(1):72-3.

49. Lewis K, Chaudhuri D, Alshamsi F, Carayannopoulos L, Dearness K, Chagla $Z$, et al. The efficacy and safety of hydroxychloroquine for COVID-19 prophylaxis: a systematic review and meta-analysis of randomized trials. PLOS ONE. 2021;16(1):e0244778.

50. Garcia P, Revet A, Yrondi A, Rousseau V, Degboe Y, Montastruc F. Psychiatric disorders and hydroxychloroquine for coronavirus disease 2019 (COVID-19): a VigiBase study. Drug Saf. 2020;43(12):1315-22.

51. Emmanuel S, Östlundh L. Psychiatric adverse events with hydroxychloroquine during COVID-19 pandemic. Asian J Psychiatr. 2020;54:102203.

52. Devarajan A, Vaseghi M. Hydroxychloroquine can potentially interfere with immune function in COVID-19 patients: mechanisms and insights. Redox Biol. 2021;38:101810.

53. Colivicchi F, Di Fusco SA, Magnanti M, Cipriani M, Imperoli G. The impact of the coronavirus disease-2019 pandemic and italian lockdown measures on clinical presentation and management of acute heart failure. J Card Fail. 2020;26(6):464-5.
54. Conti P, Caraffa A, Gallenga CE, Kritas SK, Frydas I, Younes A, et al. The British variant of the new coronavirus-19 (Sars-Cov-2) should not create a vaccine problem. J Biol Regul Homeost Agents. 2020;35(1).

55. https://virological.org/t/preliminary-genomic-characterisation-of-anemergent-sars-cov-2-lineage-in-the-uk-defined-by-a-novel-set-ofspike-mutations/563. Accessed 2020.

56. Starr TN, Greaney AJ, Hilton SK, Ellis D, Crawford KHD, Dingens AS, et al. Deep mutational scanning of SARS-CoV-2 receptor binding domain reveals constraints on folding and ACE2 binding. Cell. 2020;182(5):1295-310e20.

57. Muik A, Wallisch AK, Sanger B, Swanson KA, Muhl J, Chen W, et al. Neutralization of SARS-CoV-2 lineage B.1.1.7 pseudovirus by BNT162b2 vaccine-elicited human sera. Science. 2021.

58. Wu K, Werner AP, Moliva Jl, Koch M, Choi A, Stewart-Jones GBE, et al. mRNA-1273 vaccine induces neutralizing antibodies against spike mutants from global SARS-CoV-2 variants. BioRxiv. 2021; 2021.01.25.427948.

59. https://baijiahao.baidu.com/s?id=1690399105795983514\&wfr=spide r\&for=pc. Accessed 2020.

60. Madjid M, Safavi-Naeini P, Solomon SD, Vardeny O. Potential effects of coronaviruses on the cardiovascular system: a review. JAMA Cardiol. 2020;5(7):831-40.

61. Bavishi C, Bonow RO, Trivedi V, Abbott JD, Messerli FH, Bhatt DL. Special article-acute myocardial injury in patients hospitalized with COVID-19 infection: a review. Prog Cardiovasc Dis. 2020;63(5):682-9.

62. Puntmann VO, Carerj ML, Wieters I, Fahim M, Arendt C, Hoffmann J, et al Outcomes of cardiovascular magnetic resonance imaging in patients recently recovered from coronavirus disease 2019 (COVID-19). JAMA Cardiol. 2020;5(11):1265-73.

63. Salehi S, Abedi A, Balakrishnan S, Gholamrezanezhad A. Coronavirus disease 2019 (COVID-19): a systematic review of imaging findings in 919 patients. AJR Am J Roentgenol. 2020;215(1):87-93.

64. Salehi S, Abedi A, Balakrishnan S, Gholamrezanezhad A. Coronavirus disease 2019 (COVID-19) imaging reporting and data system (COVIDRADS) and common lexicon: a proposal based on the imaging data of 37 studies. Eur Radiol. 2020;30(9):4930-42.

65. Salehi S, Reddy S, Gholamrezanezhad A. Long-term pulmonary consequences of coronavirus disease 2019 (COVID-19): what we know and what to expect. J Thorac Imaging. 2020;35(4):W87-9.

66. Ngai JC, Ko FW, Ng SS, To KW, Tong M, Hui DS. The long-term impact of severe acute respiratory syndrome on pulmonary function, exercise capacity and health status. Respirology. 2010;15(3):543-50.

67. Carfi A, Bernabei R, Landi F, Gemelli Against C-P-ACSG. Persistent symptoms in patients after acute COVID-19. JAMA. 2020;324(6):603-5.

68. Zhu WF, Zhao JQ, Liu XL, Guan YM, Jin C, Yang M, et al. Study on fingerprint of polysaccharides from Jinshuibao Capsule. Chin Tradit Herbal Drugs. 2017;48(16):3322-6.

69. Gen HW, Hu XH. Effect of Jinshuibao capsule in the treatment of 60 cases of chronic obstructive pulmonary disease. Tradit Chin Med Res. 2000;04:40-1.

70. Xie WT, Li MQ. Effect of Jinshuibao Capsule on pulmonary function and immune function in stable patients with chronic obstructive pulmonary disease. Chin J Exp Tradit Med Formulae. 2014;20(23):217-20.

71. Xun X. Research of influence by Jinshuibao capsules on pulmonary function in chronic obstructive pulmonary disease patients. Chin J Modern Drug Appl. 2015;9(16):15-7.

72. Hu R, Yang Y, Bai HB, Fu XC. Effect of cordyceps polysaccharide on pingyangmycin induced pulmonary fibrosis in mice. Chin J Modern Drug Appl. 2019;36(13):1639-42.

73. Zhang SH, Ding QQ. Experimental study of cordyceps sinensis powder in the treatment of acute lung injury in rats. Chin J Ethnomed Ethnopharm. 2016;25(05):81-3.

74. Zheng YQ. Influence of traditional Chinese medicine Jinshuibao capsule on levels of serum cytokines in the patients with chronic obstructive pulmonary disease. China J Modern Med. 2010;20(07):1096-8.

75. Guo QZ. Effect of Jin-Shui-Bao and Dexamethasone on expression of Aquaporin $1 \mathrm{in}$ lung tissue of acute bronchial asthma SD rats [Mastership dissertation]: Nanchang University; 2011.

76. Li F, Cheng TF, Dong X, Li P, Yang H. Global analysis of chemical constituents in Shengmai injection using high performance liquid 
chromatography coupled with tandem mass spectrometry. J Pharm Biomed Anal. 2016;117:61-72.

77. Huang $X$, Duan $X$, Wang $K$, Wu J, Zhang $X$. Shengmai injection as an adjunctive therapy for the treatment of chronic obstructive pulmonary disease: a systematic review and meta-analysis. Complement Ther Med. 2019:43:140-7.

78. Tian J, Tang W, Xu M, Zhang C, Zhao P, Cao T, et al. Shengmai San alleviates diabetic cardiomyopathy through improvement of mitochondrial lipid metabolic disorder. Cell Physiol Biochem. 2018;50(5):1726-39.

79. Jiang Y, He Q, Zhang T, Xiang W, Long Z, Wu S. Exploring the mechanism of Shengmai Yin for coronary heart disease based on systematic pharmacology and chemoinformatics. Biosci Rep. 2020;40(6).

80. Chen Q, Zhang P, Xiao QX, Liu Q, Zhang Y. Protective effect of Shengmai injection on myocardial endothelial cell glycoprotein detachment after myocardial ischemia-reperfusion injury in isolated rat hearts. Perfusion. 2020;2020:267659120965921.

81. Li Q, Xiang Y, Chen Y, Tang Y, Zhang Y. Ginsenoside Rg1 protects cardiomyocytes against hypoxia/reoxygenation injury via activation of Nrf2/HO-1 signaling and inhibition of JNK. Cell Physiol Biochem. 2017:44(1):21-37.

82. Zheng Q, Bao XY, Zhu PC, Tong Q, Zheng GQ, Wang Y. Ginsenoside Rb1 for myocardial ischemia/reperfusion injury: preclinical evidence and possible mechanisms. Oxid Med Cell Longev. 2017;2017:6313625.

83. Xu ZM, Li CB, Liu QL, Li P, Yang H. Ginsenoside Rg1 prevents doxorubicin-induced cardiotoxicity through the inhibition of autophagy and endoplasmic reticulum stress in mice. Int J Mol Sci. 2018;19(11):3658.

84. Peng L, Sun S, Xie LH, Wicks SM, Xie JT. Ginsenoside Re: pharmacological effects on cardiovascular system. Cardiovasc Ther. 2012;30(4):e183-8.

85. Wang QL, Yang L, Peng Y, Gao M, Yang MS, Xing W, et al. Ginsenoside Rg1 regulates SIRT1 to ameliorate sepsis-induced lung inflammation and injury via inhibiting endoplasmic reticulum stress and inflammation. Mediators Inflamm. 2019;2019:6453296.

86. Chen MH, Chen XJ, Wang M, Lin LG, Wang YT. Ophiopogon japonicasa phytochemical, ethnomedicinal and pharmacological review. J Ethnopharmacol. 2016;181:193-213.

87. Hung TM, Thu CV, Dat NT, Ryoo SW, Lee JH, Kim JC, et al. Homoisoflavonoid derivatives from the roots of Ophiopogon japonicus and their in vitro anti-inflammation activity. Bioorg Med Chem Lett. 2010;20(8):2412-6.

88. Zhong S, Nie YC, Gan ZY, Liu XD, Fang ZF, Zhong BN, et al. Effects of Schisandra chinensis extracts on cough and pulmonary inflammation in a cough hypersensitivity guinea pig model induced by cigarette smoke exposure. J Ethnopharmacol. 2015;165:73-82.

89. You JS, Pan TL, Hou YC. Schisandra chinensis protects against adriamycin-induced cardiotoxicity in rats. Chang Gung Med J. 2006;29(1):63-70.

90. Rogers JP, Chesney E, Oliver D, Pollak TA, McGuire P, Fusar-Poli P, et al. Psychiatric and neuropsychiatric presentations associated with severe coronavirus infections: a systematic review and meta-analysis with comparison to the COVID-19 pandemic. Lancet Psychiatry. 2020;7(7):611-27.

91. Mak IW, Chu CM, Pan PC, Yiu MG, Chan VL. Long-term psychiatric morbidities among SARS survivors. Gen Hosp Psychiatry. 2009:31 (4):318-26.

92. Ahmed H, Patel K, Greenwood DC, Halpin S, Lewthwaite P, Salawu A, et al. Long-term clinical outcomes in survivors of severe acute respiratory syndrome and Middle East respiratory syndrome coronavirus outbreaks after hospitalisation or ICU admission: a systematic review and meta-analysis. J Rehabil Med. 2020;52(5):jrm00063.

93. Baloch S, Baloch MA, Zheng T, Pei X. The coronavirus disease 2019 (COVID-19) pandemic. Tohoku J Exp Med. 2020;250(4):271-8.

94. Franic T, Dodig-Curkovic K. Covid-19, child and adolescent mental health—croatian (in)experience. Ir J Psychol Med. 2020:37(3):214-7.

95. McKay D, Yang H, Elhai J, Asmundson GJG. Anxiety regarding contracting COVID-19 related to interoceptive anxiety sensations: the moderating role of disgust propensity and sensitivity. J Anxiety Disord. 2020;73:102233.

96. Pappa S, Ntella V, Giannakas T, Giannakoulis VG, Papoutsi E, Katsaounou P. Prevalence of depression, anxiety, and insomnia among healthcare workers during the COVID-19 pandemic: a systematic review and metaanalysis. Brain Behav Immun. 2020;88:901-7.
97. Mao L, Jin H, Wang M, Hu Y, Chen S, He Q, et al. Neurologic manifestations of hospitalized patients with coronavirus disease 2019 in Wuhan, China. JAMA Neurol. 2020;77(6):683-90.

98. Huang $Y$, Wang Y, Zeng L, Yang J, Song X, Rao W, et al. Prevalence and correlation of anxiety, insomnia and somatic symptoms in a Chinese population during the COVID-19 epidemic. Front Psychiatry. 2020;11:568329.

99. Talih F, Ajaltouni J, Ghandour H, Abu-Mohammad AS, Kobeissy F. Insomnia in hospitalized psychiatric patients: prevalence and associated factors. Neuropsychiatr Dis Treat. 2018;14:969-75.

100. Wang C, Pan R, Wan X, Tan Y, Xu L, Ho CS, et al. Immediate psychological responses and associated factors during the initial stage of the 2019 coronavirus disease (COVID-19) epidemic among the general population in China. Int J Environ Res Public Health. 2020;17(5):1729.

101. Pfefferbaum B, North CS. Mental health and the Covid-19 pandemic. N Engl J Med. 2020;383(6):510-2.

102. Passavanti M, Argentieri A, Barbieri DM, Lou B, Wijayaratna K, Foroutan Mirhosseini AS, et al. The psychological impact of COVID-19 and restrictive measures in the world. J Affect Disord. 2021;283:36-51.

103. Yan Y, Li Q, Du HZ, Shen CX, Li AP, Pei XP, et al. Determination of five neurotransmitters in the rat brain for the study of the hypnotic effects of Ziziphi Spinosae Semen aqueous extract on insomnia rat model by UPLC-MS/MS. Chin J Nat Med. 2019;17(7):551-60.

104. Cao JX, Zhang QY, Cui SY, Cui XY, Zhang J, Zhang YH, et al. Hypnotic effect of jujubosides from Semen Ziziphi Spinosae. J Ethnopharmacol. 2010;130(1):163-6.

105. Yang L, Shergis JL, Di YM, Zhang AL, Lu C, Guo X, et al. Managing depression with Bupleurum chinense herbal formula: a systematic review and meta-analysis of randomized controlled trials. J Altern Complement Med. 2020;26(1):8-24.

106. Feng $Y$, Gao X, Meng M, Xue H, Qin X. Multi-omics reveals the mechanisms of antidepressant-like effects of the low polarity fraction of Bupleuri Radix. J Ethnopharmacol. 2020;256:112806.

107. Wang YL, Wang JX, Hu XX, Chen L, Qiu ZK, Zhao N, et al. Antidepressantlike effects of albiflorin extracted from Radix paeoniae Alba. J Ethnopharmacol. 2016;179:9-15.

108. Li X, Qin XM, Tian JS, Gao XX, Du GH, Zhou YZ. Integrated network pharmacology and metabolomics to dissect the combination mechanisms of Bupleurum chinense DC-Paeonia lactiflora Pall herb pair for treating depression. J Ethnopharmacol. 2021;264:113281.

109. Wang Y, Gao SM, Li R, Zhang M, Gao S, Yu CQ. Antidepressant-like effects of the Radix Bupleuri and Radix Paeoniae Alba drug pair. Neurosci Lett. 2016;633:14-20.

110. Kang TH, Jeong SJ, Kim NY, Higuchi R, Kim YC. Sedative activity of two flavonol glycosides isolated from the flowers of Albizzia julibrissin Durazz. J Ethnopharmacol. 2000:71(1-2):321-3.

111. Jung JW, Cho JH, Ahn NY, Oh HR, Kim SY, Jang CG, et al. Effect of chronic Albizzia julibrissin treatment on 5-hydroxytryptamine1 A receptors in rat brain. Pharmacol Biochem Behav. 2005:81(1):205-10.

112. Xu C, Shang SY, Liu M, Yang M. Research progress on chemical constituents and pharmacological activities of Bombyx Mori. China Pharm. 2014;25(39):3732-4.

113. Hu PF, Wang JP, Fan RP, Chen XJ, Xu YX, Pang CY. Study on the sedation of Bombyx Batryicatus. Lishizhen Med Mater Med Res. 2005;1 1:1113-4.

114. Zhou CM, Wang XC. Analysis of trace elements in gecko, mylabris, bombyx mori, and cicada sloughs. J Chin Med Mater. 1991;02:14-5.

115. Yuan BY. Analysis of trace elements and amino acids in cicada sloughs. China J Chin Mater Med. 1990;12:35-6.

116. An L. Anticonvulsant activity of Periostr acum Cicadae. Chin Med Herald. 2008;15:35-6.

117. Shan $\mathrm{CY}$, Ye YH, Jiang HF, Zhang J. Study on chemical constituents isolated from juncus effuses. J Chin Med Mater. 2008:03:374-6.

118. Li GY, Wang XH, Yang LH, Zhao DD, Guo ZY, Huang JM. Recognition of anxiolytic constituents from Juncus effusus based on constituents knock-out technique. Chin Tradit Herbal Drugs. 2014;45(06):825-7.

119. Wang YL, Huang JM, Zhang SF, Sun JN. Sedative fraction from Juncus effuses L. J Beijing Univ Tradit Chin Med. 2006;03:181-3.

120. Wei H, Peng Y, Ma GX, Xu LJ, Xiao PG. Advances in studies on active components of Saussurea lappa and their pharmacological actions. Chin Tradit Herbal Drugs. 2012;43(03):613-20. 
121. Chen SF, Li YQ, He FY, Pan LL. Effect of Saussurea on lappa on Gastric Function. Chin J Integr Tradit Western Med. 1994;07:406-8.

122. Zhou XM, Zhang LM, Cao YL, Song QL, Li Y. Effect of muxiang dynamics capsules inclusion (MDCl) on gastric emptying in mice. J Shenyang Pharmaceu Univ. 2003;03:207-9.

123. Hou Y, Zhang $X$. Effects of radix aucklandiae on small intestine movement in normal rats. J Chin Med. 2019;34(09):1921-5.

124. Zeng Z, Xi ZC, Meng SJ, Pang SM, Xie RQ, Ye XN, et al. Study on volatile constitutions and quality evaluation of different varieties of fructus amomis. J Instrum Anal. 2010;29(07):701-6.

125. Zhang ST, Wang ZY, Wang TS, Li MX, Lin JM. Composition and antimicrobial activities of essential oil of fructus amomi. Nat Product Res Dev. 2011:23(03):464-72.

126. Zhu JZ, Leng ER, Chen DF, Zhang J. Effects of amomum villosum on gastrointestinal motility and neurotransmitters in rats. Chin J Integr Tradit Western Med Digest. 2001;04:205-7.

127. Zhu JZ, Zhang J, Zhang ZJ, Wang W. Effects of Amomum villosum on functional digestion disorder in rats. West China J Pharmaceu Sci. 2006;01:58-60.

128. $L Y L$, Yao L, Zhang JP, Lin $B Q, H u X B$. Research advance on chemical constituents of Radix Codonopsis. Shandong J Pharmaceut. 1999(01):35-6.

129. Li J, Wang T, Zhu Z, Yang F, Cao L, Gao J. Structure features and antigastric ulcer effects of inulin-type fructan CP-A from the roots of Codonopsis pilosula (Franch) Nannf. Molecules. 2017;22(12):2258.

130. Guo JP, Meng C, Liu HY. Effects of qi tonifying herbs on gastrointestinal motility and hormone levels in mice. Chin J Gerontol. 2015;35(11):2920-1

131. Lu YJ, Lian ZC. Effects of gastrointestinal hormones on gastrointestinal motility. Immunol J. 2006:S1:94-6.

132. Shui DK, Xie S. Effect of Xuanfu Daizhe decoction on motilin, gastrin and vasoactive intestinal peptide in blood and tissuein rats with low gastric motility. Chin J Exp Tradit Med Formulae. 2011;17(11):161-4.

133. Ma FL, Shen XM, Shi J. Effect of codonopsis polysaccharide on gastrointestinal tract of experimental rats and mice. Anhui Med Pharmaceut J. 2014;18(09):1626-30.

134. Yang E, Zhong YM, Feng YF. Advance on the chemical constituents and pharmacological effects of Atractylodes macrocephala Koidz. J Guangdong College Pharm. 2012;28(02):218-21.

135. Yan WL, Wang SS, Ren X. Experimental study of atractylodes on intestinal microflora in mice. Shandong J Tradit Chin Med. 2011;30(06):417-9.

136. Li W, Wen HM, Cui XB, Li X, Hong M. Effective components of rhizoma atractylodis macrocephalae in invigorating spleen. J Nanjing Univ Tradit Chin Med. 2006;06:366-7.

137. Ma XS, Fan XP, Chen Z, Li CW, Xing YS. Effects of rhizoma atractylodis macrocephalae on the contraction of isolated ileum of guinea pig. J N Digest Syst Dis. 1996;11:603-4.

138. Ma L, Yin L, Wang B, Zhao X, Fu XY. Research progress of Poria ocos. Asia-Pacific Tradit Med. 2015;11(12):55-9.

139. Peng C. Pharmacology of traditional Chinese Medicine. Beijing: China traditional Chinese Medicine Press; 2012. p. 183.
140. Li X, Li Y. The research progress of the pharmacological function of active components extracted from Gancao, Jiangsu. J Tradit Chin Med. 2019;51(05):81-6.

141. LV GY, Yu LX. Effects of processed liquorice products on the activity of isolated intestine in rabbits. Tradit Chin Med J. 1986;09:21-3.

142. Li QY, Liang SL, Chu HB, Yang YJ, Yan FG. Study on the active parts of Citri Reticulatae Pericarpium in increasing gastrointestinal motility. Chin Tradit Patent Med. 2012;34(05):941-3.

143. Fu MQ, Xiao GS, Wu JJ, Chen YL, Wen J, Xu YJ. Studies on chemical basis of digestion promoting function of pericarpium citri reticulatae (Citrus reticulate 'Chachi'). J Chin Inst Food Sci Technol. 2018;18(01):56-64.

144. Mao QF, Liu WH, Jin H, Che Y, Shen K, Fan ZZ. Isolation of endophyte and screening for antagonistic bacteria in Pinellia. Chin Arch Tradit Chin Med. 2014;32(08):1838-41.

145. Liu SY, You CL, Wang YM. Experimental study on the mechanism of antiulcer effect of Pinellia Ternate. Liaoning J Tradit Chin Med. 1992;10:42-5.

146. Zhao WZ, Zhang RX, Yu ZP, Wang XK, Li JR, Liu JB. Research process in ginger chemical composition and biological activity. Sci Technol Food Industry. 2016;37(11):383-9.

147. Platel K, Srinivasan K. Influence of dietary spices or their active principles on digestive enzymes of small intestinal mucosa in rats. Int J Food Sci Nutr. 1996:47(1):55-9.

148. Ding S, Wang X. Protective effect of ginger on gastric ulceration induced by aspirin in rats Chinese. J Ethnomed Ethnopharm. 2012;21(21):22+4.

149. Liu SJ, Tang ZS, Cui CL, Liu HD, Liang YN, Zhang Y, et al. Advances in studies on chemical constituents of Ziziphus jujuba. J Yunnan Univ Tradit Chin Med. 2015;38(03):96-100.

150. Huang YL, Yen GC, Sheu F, Chau CF. Effects of water-soluble carbohydrate concentrate from Chinese jujube on different intestinal and fecal indices. J Agric Food Chem. 2008;56(5):1734-9.

151. Naftali T, Feingelernt H, Lesin Y, Rauchwarger A, Konikoff FM. Ziziphus jujuba extract for the treatment of chronic idiopathic constipation: a controlled clinical trial. Digestion. 2008;78(4):224-8.

152. Zhang X, Gen AP. Experimental study on Lu-Dangshen in pharmacology. Lishizhen Med Mater Med Res. 2001;06:488-9.

153. Zheng Y, Jin $\sqcup$, Zhang Y, Tian J, Lian F, et al. Understanding COVID-19 in Wuhan from the perspective of cold-dampness: clinical evidences and mechanisms. Front Med (Lausanne). 2021:8:617659.

154. An X, Zhang Y, Duan L, Zhao S, Zhou R, et al. The direct evidence and mechanism of traditional Chinese medicine treatment of COVID-19. Biomed Pharmacother. 2021;137:111267.

\section{Publisher's Note}

Springer Nature remains neutral with regard to jurisdictional claims in published maps and institutional affiliations.

Ready to submit your research? Choose BMC and benefit from

- fast, convenient online submission

- thorough peer review by experienced researchers in your field

- rapid publication on acceptance

- support for research data, including large and complex data types

- gold Open Access which fosters wider collaboration and increased citations

- maximum visibility for your research: over 100M website views per year

At BMC, research is always in progress.

Learn more biomedcentral.com/submissions 